University of Nebraska - Lincoln

DigitalCommons@University of Nebraska - Lincoln

Public Health Resources

Public Health Resources

1998

\title{
Increasing Prevalence of Overweight Among US Low-income Preschool Children: The Centers for Disease Control and Prevention Pediatric Nutrition Surveillance, 1983 to 1995
}

\author{
Zuguo Mei \\ Centers for Disease Control and Prevention, Atlanta, Georgia \\ Kelley S. Scanlon \\ Centers for Disease Control and Prevention, Atlanta, Georgia \\ Laurence M. Grummer-Strawn \\ Centers for Disease Control and Prevention, Atlanta, Georgia \\ David S. Freedman \\ Centers for Disease Control and Prevention, Atlanta, Georgia \\ Ray Yip \\ United Nations Children's Fund (UNICEF), Jakarta, Indonesia \\ See next page for additional authors
}

Follow this and additional works at: http://digitalcommons.unl.edu/publichealthresources

Mei, Zuguo; Scanlon, Kelley S.; Grummer-Strawn, Laurence M.; Freedman, David S.; Yip, Ray; and Trowbridge, Frederick L., "Increasing Prevalence of Overweight Among US Low-income Preschool Children: The Centers for Disease Control and Prevention Pediatric Nutrition Surveillance, 1983 to 1995" (1998). Public Health Resources. 466.

http://digitalcommons.unl.edu/publichealthresources/466

This Article is brought to you for free and open access by the Public Health Resources at DigitalCommons@University of Nebraska - Lincoln. It has been accepted for inclusion in Public Health Resources by an authorized administrator of DigitalCommons@University of Nebraska - Lincoln. 


\section{Authors}

Zuguo Mei, Kelley S. Scanlon, Laurence M. Grummer-Strawn, David S. Freedman, Ray Yip, and Frederick L. Trowbridge 


\title{
Increasing Prevalence of Overweight Among US Low-income Preschool Children: The Centers for Disease Control and Prevention Pediatric Nutrition Surveillance, 1983 to 1995
}

\author{
Zuguo Mei, MD, MPH*; Kelley S. Scanlon, PhD, RD*; Laurence M. Grummer-Strawn, PhD*; \\ David S. Freedman, PhD*; Ray Yip, MD, MPH‡; Frederick L. Trowbridge, MD, MSc*
}

\begin{abstract}
Objective. To determine whether the prevalence of overweight in preschool children has increased among the US low-income population.

Design. Analysis using weight-for-height percentiles of surveillance data adjusted for age, sex, and race or ethnicity.

Setting. Data from 18 states and the District of Columbia were examined. ${ }^{a}$

Subjects. Low-income children $<5$ years of age who were included in the Centers for Disease Control and Prevention Pediatric Nutrition Surveillance System.

Results. The prevalence of overweight increased from $18.6 \%$ in 1983 to $21.6 \%$ in 1995 based on the 85 th percentile cutoff point for weight-for-height, and from $8.5 \%$ to $10.2 \%$ for the same period based on the 95th percentile cutoff point. Analyses by single age, sex, and race or ethnic group (non-Hispanic white, non-Hispanic black, and Hispanic) all showed increases in the prevalence of overweight, although changes are greatest for older preschool children.

Conclusion. Overweight is an increasing public health problem among preschool children in the US low-income population. Additional research is needed to explore the cause of the trend observed and to find effective strategies for overweight prevention beginning in the preschool years. Pediatrics 1998;101(1). URL: http://www.pediatrics. org/cgi/content/full/101/1/e12; overweight, obesity, prevalence, preschool children, weight-for-height.
\end{abstract}

ABBREVIATIONS. NHANES, National Health and Nutrition Examination Survey; CDC, Centers for Disease Control and Prevention; WIC, Special Supplemental Nutrition Program for Women, Infants, and Children; PedNSS, Pediatric Nutrition Surveillance System.

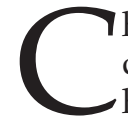
hildhood obesity is an increasing problem in developed countries and an increasing public health concern. ${ }^{1-5}$ Researchers have found an association between obesity in childhood and higher levels of blood pressure, ${ }^{6-8}$ diabetes, ${ }^{9,10}$ respiratory disease, ${ }^{11}$ adult obesity, ${ }^{12}$ and orthopedic ${ }^{13,14}$ and psy-

From the *Division of Nutrition and Physical Activity, Centers for Disease Control and Prevention, Atlanta, Georgia; and the $\ddagger$ United Nations Children's Fund (UNICEF), Jakarta, Indonesia.

Received for publication Jun 28, 1996; accepted Sep 12, 1997.

Reprint requests to (Z.M.) Centers for Disease Control and Prevention, Mailstop K-25, 4770 Buford Hwy, Atlanta, GA 30341-3724.

aAlabama, Arizona, Colorado, Connecticut, Florida, Iowa, Idaho, Illinois, Indiana, Kansas, Kentucky, Louisiana, Nebraska, New Jersey, New Mexico, Oregon, Utah, and Vermont.

PEDIATRICS (ISSN 0031 4005). Copyright (C) 1998 by the American Academy of Pediatrics.

This document is a U.S. government work and is not subject to copyright in the United States. chosocial disorders. ${ }^{15}$ Determining the factors that contribute to excess weight gain in children is of great interest, as is the question of whether the prevalence of obesity or overweight in children is increasing.

Among US children 6 to 11 years of age, Troiano et $\mathrm{al}^{2}$ reported an $\sim 7$ percentage point increase from 1963 to 1991 in the prevalence of overweight, based on a body mass index (weight/height ${ }^{2}$ ) above the 85th percentile, and a 5 percentage point increase in the prevalence based on a body mass index above the 95th percentile. Gortmaker et $\mathrm{al}^{3}$ reported a 9.5 percentage point increase from 1963 to 1980 in the prevalence of obesity for children age 6 to 11 years of age based on triceps skinfold measurements above the 85th percentile and a 5.8 percentage point increase in the prevalence of obesity above the 95th percentile of the triceps skinfold measurements. This report ${ }^{3}$ also noted that weight-for-height among children 6 and 7 years old increased during the same period. More recently, Ogden et $\mathrm{al}^{16}$ reported a greater increase for girls (2.8 percentage points at 2 to 3 years and 5.0 at 4 to 5 years) than for boys ( 1 percentage point decrease at 2 to 3 years and only a 0.6 percentage point increase at 4 to 5 years, but no statistical significance in the change of prevalence both at 2 to 3 years and at 4 to 5 years of age) in the prevalence of overweight based on the 95th percentile of weight-for-height data from the National Health and Nutrition Examination Survey I (NHANES I, 1971 to 1974) to NHANES III (1988 to 1994).

In this study, we try to determine whether the prevalence of overweight in preschool children among the US low-income population has increased also and to extend our analyses to include infants and toddlers ( 0 to 23 months of age).

\section{METHODS}

Since 1973, the Centers for Disease Control and Prevention (CDC) has assisted states in monitoring key growth and hematologic indicators of nutritional status of low-income US children who participate in publicly funded health and nutrition programs such as the Special Supplemental Nutrition Program for Women, Infants, and Children (WIC); Early Periodic Screening, Diagnosis and Treatment Program; and clinics funded through Maternal and Child Health Program block grants. ${ }^{17,18}$ Data for the majority of the infants and children monitored by the Pediatric Nutrition Surveillance System (PedNSS) come from clinic service records of WIC. The WIC program, which was initiated in 1972, is administered by the Food and Nutrition Service of the US Department of Agriculture. ${ }^{19,20}$ The PedNSS has expanded from five participating states in 1973 to 38 states, the District of Columbia, Puerto Rico, and 7 
Indian Reservations in 1995. This surveillance system provides a rich source of data for studying the nutritional characteristics of low-income children on a state-by-state basis. ${ }^{17,18}$

In the PedNSS system, height or length is measured to the nearest $0.1 \mathrm{~cm}$ or $1 / 8$ inch. According to the protocols, a measuring board is used to measure the child's recumbent length if the child is $<24$ months of age; otherwise, a standing height is measured for children $>24$ months. Weight was measured to the nearest $0.1 \mathrm{~kg}$ or $1 / 4$ pound using a pediatric scale or other beam balance scale. ${ }^{21,22}$ All the records are entered onto a standardized paper form or onto an automated computer system in the clinics. Once the records are computerized at the state level, they are transferred to the CDC for inclusion in the PedNSS database.

To study the trend in prevalence of overweight from 1983 through 1995, we selected all children 0 to 59 months old from the 18 states $^{a}$ (plus the District of Columbia) who participated consistently in the PedNSS during this period. Among the 18 states and the District of Columbia, we checked the data quality by using the anthropometric data quality assurance indexes ${ }^{22,23}$ across states and years within each state to verify whether the data are comparable. Because a nearly constant variance in height- and weightbased $z$ score distributions is indicative of data quality, ${ }^{23}$ the SD units of weight-for-height $z$ score were used to check the data quality across states and years. We found the that the SD units of the $z$ score distribution were within the normal range (0.85 to $1.10)^{23}$ and were stable. Also, we tracked the height-for-age $z$ score across years for each state included in this analysis to examine whether an increasing bias of measuring children too short could affect the overall overweight trend. We found that there was no change in the mean height-for-age $z$ score across years for all the states in the dataset. Furthermore, the records of the children with missing ages were automatically excluded before they were transferred to the PedNSS database. The percents of missing height/ length and weight were $1.5 \%$ and $1.1 \%$, respectively. The percent of records with biologically implausible values of weight-forheight $(z \text { score below }-4 \text { or above }+5)^{23}$ was $0.5 \%$.

To examine whether the criteria for enrollment in these publicly funded health and nutrition programs remained approximately the same from 1983 to 1995 in the selected 18 states and the District of Columbia, a survey was conducted in those states regarding any certification criterion or priority changes for overweight in the programs during the 13 years.

Because the PedNSS, which receives data from publicly funded health and nutrition programs, has multiple records on children per calendar year and a disproportionate number of first visit records for young infants, one record per child per visit year was randomly selected to avoid double counting of children who visit the program more than once in a calendar year. Repeat visits were identified using the unique WIC identification number, which is maintained for WIC administration. The final sample for this study was 15029147 preschooler clinic records.

To examine trends more generally for children $<5$ years old, we age-adjusted the prevalence estimates for each year, assuming a uniform age distribution. To do this, we weighted the data so that the prevalence of each single month of age was weighted equally. The results were also adjusted for race or ethnicity and for sex, assuming that the ethnic mix for all 13 years combined applies for each calendar year, and assuming that there should be $50 \%$ boys and $50 \%$ girls.

We examined trends by the urban/rural classification of the county in which the clinical measurements were taken using the Census Bureau definition of urban and rural. To examine how the CDC PedNSS low-income preschooler population differs from the US general population at the same ages, we compared the demographic and anthropometric characteristics of the PedNSS data with NHANES II and III data.

In recent years, several studies have shown that the current NCHS/CDC growth reference sections based on the Fels sample ( $<2$ years of age) and the part based on the national representative NHANES I sample ( $\geq 2$ years of age) are not comparable. When the two curves are compared, there is a clear disjunction of heightfor-age and weight-for-height at 24 months of age. . $^{2,25}$ These disjunctions make it difficult to compare the growth status of children $<2$ years of age with that of children $>2$ years of age. Because of the disjunction, we also performed the trend analysis separately for these two age groups.

There is no generally accepted definition of obesity or overweight for children and adolescents. ${ }^{26,27}$ Various criteria for overweight and obesity have been used to estimate prevalence and trends among children and adolescents. $3,28,29$ For this study, we used weight-for-height status above the 85th and 95th percentiles of the NCHS/CDC weight-for-height reference to estimate the prevalence of overweight or obesity in our study population. We calculated weight-for-height percentiles and $z$ scores by using the NCHS/CDC age- and sex-specific growth reference. ${ }^{30,31}$ Any weight-for-height $z$ scores below -4 or above +5 were excluded, because these extreme values were most likely attributable to errors in measurement or data entry. ${ }^{23}$

\section{RESULTS}

From the survey among the states and district in this study, we confirmed that each of them maintained the same overweight certification criteria for

TABLE 1. Comparison of Demographic and Anthropometric Characteristics (\%) of NHANES II and III Data With the CDC PedNSS Data

\begin{tabular}{|c|c|c|c|c|}
\hline \multirow[t]{2}{*}{ Age (mo) } & \multicolumn{2}{|c|}{ NHANES Data } & \multicolumn{2}{|c|}{ PedNSS Data } \\
\hline & $\begin{array}{l}\text { II }(1976-1980) \\
(\mathrm{N}=3298)\end{array}$ & $\begin{array}{l}\text { III }(1988-1994) \\
\quad(\mathrm{N}=6662)\end{array}$ & $\begin{array}{c}1983 \\
(\mathrm{~N}=608950)\end{array}$ & $\begin{array}{c}1995 \\
(\mathrm{~N}=1504063)\end{array}$ \\
\hline $0-5$ & - & $6.2^{*}$ & 29.2 & 25.1 \\
\hline $6-11$ & 9.6 & 10.5 & 16.5 & 10.9 \\
\hline $12-23$ & 24.0 & 20.7 & 21.3 & 22.0 \\
\hline $24-35$ & 21.5 & 21.6 & 14.5 & 16.4 \\
\hline $36-47$ & 22.9 & 21.0 & 11.1 & 13.9 \\
\hline $48-59$ & 22.0 & 20.1 & 7.3 & 11.6 \\
\hline Boys & 51.2 & 51.2 & 50.5 & 50.6 \\
\hline Girls & 48.8 & 48.8 & 49.5 & 49.4 \\
\hline Non-Hispanic white & 63.4 & 62.5 & 50.1 & 45.0 \\
\hline Non-Hispanic black & 15.2 & 16.4 & 33.1 & 29.8 \\
\hline Hispanic & 8.3 & 16.7 & 13.9 & 22.5 \\
\hline Others & 13.1 & 4.5 & 2.9 & 2.6 \\
\hline Urban & 59.6 & 52.3 & 59.3 & 66.7 \\
\hline Rural & 40.4 & 47.7 & 40.7 & 33.3 \\
\hline Mean birth weight $(\mathrm{g}) \dagger$ & $3339(582)$ & $3356(590)$ & $3217(598)$ & 3245 (593) \\
\hline Percentage of birth weight $<2500 \mathrm{~g}$ & 9.1 & 10.0 & 13.9 & 13.9 \\
\hline \multicolumn{5}{|l|}{ Mean $z$ scoret } \\
\hline Height for age & $-0.14(1.05)$ & $-0.06(1.00)$ & $-0.40(1.19)$ & $-0.32(1.17)$ \\
\hline Weight for age & $-0.11(1.04)$ & $0.05(1.04)$ & $-0.11(1.18)$ & $0.00(1.19)$ \\
\hline Weight for height & $0.08(0.90)$ & $0.19(0.95)$ & $0.22(1.08)$ & $0.30(1.06)$ \\
\hline
\end{tabular}

* Only for infants $2-5$ months of age.

+ SD units in parentheses. 
TABLE 2. Prevalence of Overweight (\%) Among Children 0-59 Months by Age Group, at 85th and 95th Percentile Cutoff Points- the CDC PedNSS, 1983 and 1995

\begin{tabular}{|c|c|c|c|c|c|c|c|c|}
\hline \multirow{3}{*}{$\begin{array}{l}\text { Age Group } \\
\text { (mo) }\end{array}$} & \multicolumn{4}{|c|}{ 85th Percentile } & \multicolumn{4}{|c|}{ 95th Percentile } \\
\hline & \multirow[t]{2}{*}{1983} & \multirow[t]{2}{*}{1995} & \multicolumn{2}{|c|}{ Increase } & \multirow[t]{2}{*}{1983} & \multirow[t]{2}{*}{1995} & \multicolumn{2}{|c|}{ Increase } \\
\hline & & & Absolute & Relative & & & Absolute & Relative \\
\hline Overall & 18.6 & 21.6 & $3.0^{*}$ & 16.1 & 8.5 & 10.2 & $1.7^{*}$ & 20.0 \\
\hline $0-11$ & 22.7 & 25.5 & $2.8^{*}$ & 12.3 & 9.9 & 11.3 & $1.4^{*}$ & 14.1 \\
\hline $12-23$ & 23.3 & 26.0 & $2.7^{*}$ & 11.6 & 12.1 & 13.7 & $1.6^{*}$ & 13.2 \\
\hline $24-35$ & 14.2 & 16.8 & $2.6^{*}$ & 18.3 & 5.6 & 7.0 & $1.4^{*}$ & 25.0 \\
\hline $36-47$ & 15.8 & 18.6 & $2.8^{*}$ & 17.7 & 7.0 & 8.5 & $1.5^{*}$ & 21.4 \\
\hline $48-59$ & 17.2 & 21.2 & $4.0^{*}$ & 23.3 & 8.2 & 10.6 & $2.4^{*}$ & 29.2 \\
\hline
\end{tabular}

* For comparison of 1983 and 1995, $P<.05$.

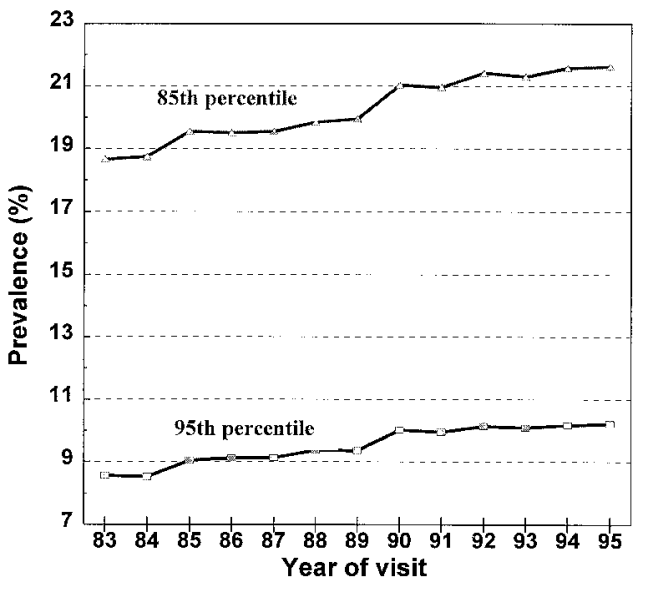

Fig 1. Prevalence of overweight (weight-for-height above 85th or 95th percentile) among US low-income children 0 to 59 months of age, adjusted by race or ethnicity, sex ratio, and age in month; the CDC Pediatric Nutrition Surveillance, 1983-1995.

preschoolers during the 13-year period, except for one state, which changed the criteria from $\geq 95$ th percentile to $\geq 90$ th percentile of weight-for-height after 1990. Exclusion of this state did not change our results. Among the preschoolers, there were no priority changes or restrictions for younger children (birth to 2 years), and only two states put the older children (age 3 to 4 years) on a waiting list or restricted program entry for a short time (1 to 3 months) in the early 1990s. However, the short time restriction did not affect the overall trend observed.

The PedNSS data showed a higher proportion of young infants and more black and Hispanic children compared with NHANES II and III data (Table 1). Also, the children in the PedNSS have a lower mean birth weight and a higher percentage of low birth weight, lower mean height-for-age, lower mean weight-for-age, and higher weight-for-height $z$ scores compared with NHANES II and III data.

The PedNSS data also showed an increasing proportion of older children from 1983 to 1995, as well as an increased proportion of Hispanic children and urban children (Table 1). The standardized adjustments in the prevalence of overweight we described in "Methods" account for these changes in demographic characteristics.

The prevalence of overweight for the children 0 to 59 months old in the period increased from $18.6 \%$ in 1983 to $21.6 \%$ in 1995 , based on the weight-for-height 85th percentile cutoff point, representing an absolute increase of 3.0 percentage points and a relative increase of $16.1 \%$. Based on the weight-for-height 95th percentile cutoff point, the prevalence increased from $8.5 \%$ in 1983 to $10.2 \%$ in 1995 , representing an absolute increase of 1.7 percentage points and a relative increase of $20 \%$ (Table 2). As shown in Fig 1, during the 13-year period, there was a consistent increase in the prevalence of overweight using both the 85th and 95th percentile cutoff points.

When we examine trends by single year of age, we see a similar trend in the prevalence of overweight from 1983 through 1995, with an increase observed for each year of age (Table 2). However, the increase in the prevalence of overweight is greatest for 48- to 59-month-old children, in both absolute and relative terms. Figure 2 (A and B) shows the age-specific trends in the prevalence of overweight based on the 95th percentile cutoff point. The trend is similar at the 85th percentile cutoff point (results available on request).

When we compare the prevalence of overweight by sex, boys and girls show a parallel increase in the prevalence of overweight at both the 85th and 95th percentile cutoff points. Among children $>24$ months of age, there is an absolute increase of 2.9 percentage points for boys and 3.4 percentage points for girls using the 85th percentile. Using the 95th percentile, there is a 1.7 percentage point increase for boys and a 1.8-percentage point for girls (Table 3). The prevalence of overweight for girls is significantly higher than for boys $(P<.05)$.

The non-Hispanic white, non-Hispanic black, and Hispanic subgroups all demonstrated an increasing trend in the prevalence of overweight from 1983 through 1995 (Fig 3 for the children $>2$ years of age using the 95th percentile). Among those children $<2$ years old, non-Hispanic whites had the largest absolute increase in prevalence of overweight. For children $>2$ years of age, non-Hispanic blacks had the largest absolute increase in prevalence of overweight, at both the 85th and the 95th percentile cutoff points (Table 3). The prevalence of overweight for Hispanics is significantly higher than for nonHispanic blacks, and for non-Hispanic blacks is significantly higher than for non-Hispanic whites $(P<.05)$.

When we compare the prevalence of overweight by clinic settings, both urban and rural clinics showed an increasing trend in the prevalence of 
A
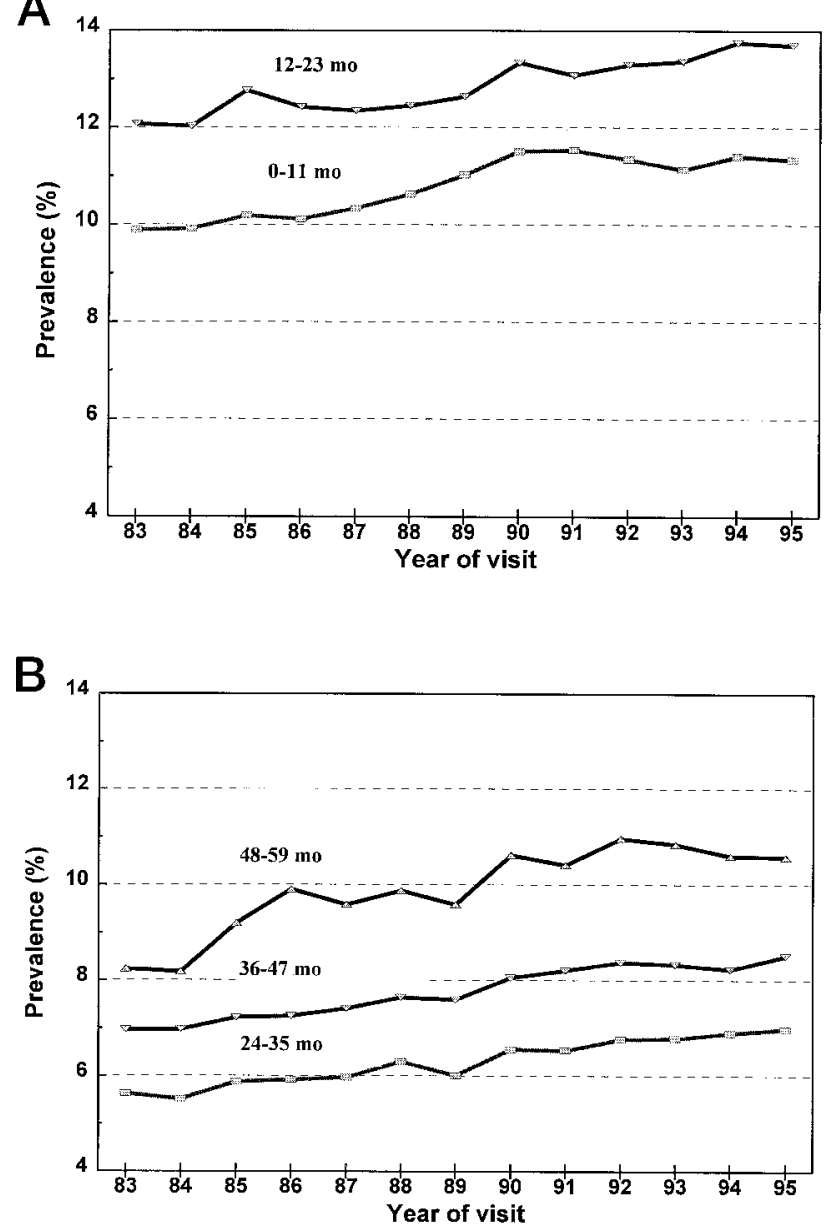

Fig 2. Age-specific prevalence of overweight (weight-for-height above 95th percentile) among US low-income children 0 to 23 months months of age (A) and 24 to 59 months of age (B), adjusted by race or ethnicity, sex ratio, and age in month; the CDC Pediatric Nutrition Surveillance, 1983-1995.

overweight from 1983 to 1995 (Table 3). Among children $>24$ months of age, there is an absolute increase of 3.3 percentage points for urban children and of 1.6 percentage points for rural children, using the 85th percentile. Using the 95th percentile, there is a 2.0 percentage point increase for urban and a 0.7 for rural (Table 3). However, the increasing trend in rural is not consistent during the 13-year period; there is a downward trend between 1989 and 1991.

To decide whether the increase in the prevalence of overweight among US low-income preschool children was related to an increase in a subpopulation of children who were heavier or to a general shift of the entire weight distribution, we used the weight-forheight $z$ score to compare the height-standardized weight distribution for the preschool children using records from 1983 and 1995. The 5th, 10th, 25th, 50th, 75 th, 90 th, and 95 th percentiles increase by $0.14,0.15$, $0.12,0.07,0.08,0.08,0.11 z$ score, respectively, from 1983 to 1995 . Also, the weight-for-height distribution of the two periods had a similar variance and shape. Thus, the increase in the prevalence of overweight observed among US low-income preschool children reflects a general upward shift in the weight distri- bution over the 13-year period rather than simply an increase in the size of the upper tail.

\section{DISCUSSION}

We found that from 1983 through 1995, there was a consistent increase in the prevalence of overweight among low-income preschool children in the United States. The increase in the prevalence of overweight is the result of a general upward shift of the weightfor-height distribution in the population. This same trend has been documented in the US population in preschool children, ${ }^{16}$ school children, ${ }^{2,32}$ adolescents, ${ }^{2,32,33}$ and adults. ${ }^{32,34-36}$ Our analysis has demonstrated that these trends are observed even before the age of 24 months. This evidence suggests that the entire population in the United States is getting heavier.

The increasing prevalence of overweight was also observed for each age, sex, and racial/ethnic group. These data suggest that underlying causes of the differences in overweight prevalence by gender, and between racial/ethnic groups observed among adults, ${ }^{32,34,36}$ and between school children and adolescents $^{32,33,37}$ may also be observed in preschool children.

There is an increasing trend in the relative increases with age. Children 48 to 59 months of age have the highest relative increase in the prevalence of overweight compared with other age groups. This confirms the result from the NHANES study for preschoolers $^{16}$ that the prevalence of overweight increase with age.

The prevalence of overweight is higher for girls compared with boys. Also, we observed a parallel increase in the prevalence of overweight between boys and girls among the low-income preschoolers, whereas data from NHANES III $^{16}$ showed a greater increase for girls (2.8 percentage points at 2 to 3 years and 5.0 percentage points at 4 to 5 years) than for boys (1.0 percentage point decrease at 2 to 3 years and only a 0.6 percentage point increase at 4 to 5 years, but no statistical significance in the change of prevalence at both 2 to 3 years and 4 to 5 years of age). It is not clear whether this inconsistency reflects true difference in trends for the WIC population or results from methodologic differences. Additional research is needed to understand fully the difference in gender behaviors for different socioeconomic strata.

Hispanic children have a higher prevalence than other race or ethnic groups. The higher prevalence of overweight among Hispanic preschool children may be related partially to dietary, environmental, or genetic factors. The growth in height and weight of well-fed, healthy children at least $<5$ years old from different ethnic backgrounds and different continents is reasonably similar. ${ }^{38-40}$ On the other hand, Trowbridge et $\mathrm{a}^{41}$ have suggested that high weightfor-height in Hispanics is associated with lower body fat.

We observed an increase in the prevalence of overweight among both urban and rural children, although trends were more marked and consistent in the urban areas. Additional research is needed to 
TABLE 3. Prevalence of Overweight (\%) Among Children 0-59 Months by Age Group, Sex, and Race or Ethnicity, at 85th and 95th Percentile Cutoff Points-the CDC PedNSS, 1983 and 1995

\begin{tabular}{|c|c|c|c|c|c|c|c|c|}
\hline \multirow[t]{3}{*}{ Age Group } & \multicolumn{4}{|c|}{ 85th Percentile } & \multicolumn{4}{|c|}{ 95th Percentile } \\
\hline & \multirow[t]{2}{*}{1983} & \multirow[t]{2}{*}{1995} & \multicolumn{2}{|c|}{ Increase } & \multirow[t]{2}{*}{1983} & \multirow[t]{2}{*}{1995} & \multicolumn{2}{|c|}{ Increase } \\
\hline & & & Absolute & Relative & & & Absolute & Relative \\
\hline \multicolumn{9}{|l|}{ 0-23 Months } \\
\hline Boys & 22.0 & 24.5 & $2.5^{*}$ & 11.4 & 10.1 & 11.4 & $1.3^{*}$ & 13.2 \\
\hline Girls & 24.0 & 27.0 & $3.0^{*}$ & 12.5 & 11.8 & 13.6 & $1.8^{*}$ & 14.7 \\
\hline \multicolumn{9}{|l|}{ 24-59 Months } \\
\hline Boys & 15.5 & 18.4 & $2.9^{*}$ & 18.7 & 6.6 & 8.3 & $1.7^{*}$ & 24.8 \\
\hline Girls & 16.0 & 19.4 & $3.4^{*}$ & 21.3 & 7.2 & 9.0 & $1.8^{*}$ & 25.5 \\
\hline \multicolumn{9}{|l|}{ 0-23 Months } \\
\hline Non-Hispanic white & 20.5 & 23.7 & $3.2^{*}$ & 15.6 & 9.0 & 10.8 & $1.8^{*}$ & 19.0 \\
\hline Non-Hispanic black & 24.7 & 26.9 & $2.2^{*}$ & 8.9 & 12.3 & 13.7 & $1.4^{*}$ & 10.9 \\
\hline Hispanic & 25.7 & 28.7 & $3.0^{*}$ & 11.7 & 12.9 & 14.5 & $1.6^{*}$ & 12.3 \\
\hline Otherst & 25.6 & 25.1 & -0.5 & -2.0 & 12.6 & 12.8 & 0.2 & 1.6 \\
\hline \multicolumn{9}{|l|}{ 24-59 Months } \\
\hline Non-Hispanic white & 13.7 & 16.7 & $3.0^{*}$ & 21.9 & 5.5 & 7.0 & $1.5^{*}$ & 28.0 \\
\hline Non-Hispanic black & 14.4 & 18.7 & $4.3^{*}$ & 29.9 & 6.1 & 8.7 & $2.6^{*}$ & 41.9 \\
\hline Hispanic & 21.1 & 23.3 & $2.2^{*}$ & 10.4 & 10.5 & 11.9 & $1.4^{*}$ & 13.5 \\
\hline Otherst & 19.9 & 20.6 & 0.7 & 3.5 & 10.4 & 9.6 & -0.8 & -8.0 \\
\hline \multicolumn{9}{|l|}{ 0-23 Months } \\
\hline Urban & 21.8 & 25.1 & $3.3^{*}$ & 15.1 & 10.3 & 12.1 & $1.8^{*}$ & 17.5 \\
\hline Rural & 23.6 & 25.9 & $2.3^{*}$ & 9.7 & 11.5 & 12.4 & $0.9^{*}$ & 7.8 \\
\hline \multicolumn{9}{|l|}{ 24-59 Months } \\
\hline Urban & 15.2 & 18.5 & $3.3^{*}$ & 21.7 & 6.6 & 8.6 & $2.0^{*}$ & 30.3 \\
\hline Rural & 16.9 & 18.5 & $1.6^{*}$ & 9.5 & 7.6 & 8.3 & $0.7^{*}$ & 9.2 \\
\hline
\end{tabular}

* For comparison of 1983 and $1995, P<.05$.

† Includes races or ethnicities other than white, black, and Hispanic.

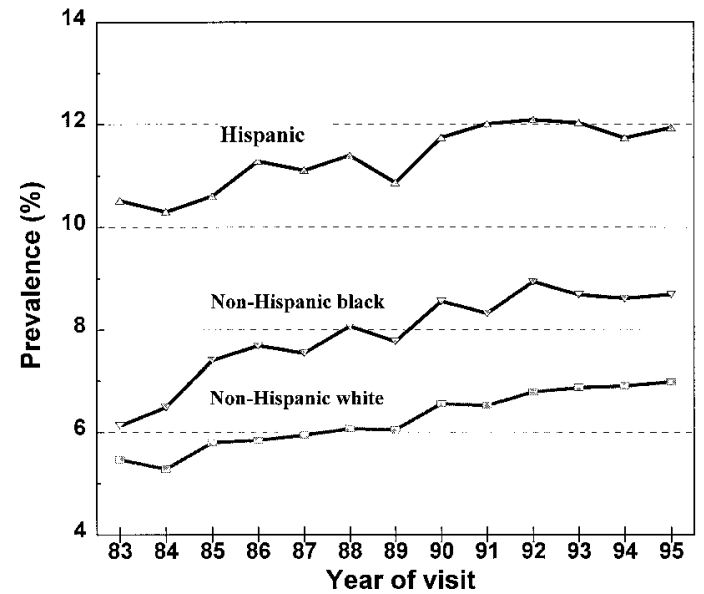

Fig 3. Prevalence by race or ethnicity of overweight (weight-forheight above 95th percentile) among US low-income children 24 to 59 months of age, adjusted by sex ratio, and age in month; the CDC Pediatric Nutrition Surveillance, 1983-1995.

understand fully the difference in behaviors in different geographic settings for other socioeconomic strata.

Our study has potential limitations commonly found in surveillance systems that use routine clinical data. Because the data come from multiple clinics and the techniques of measurement are not tightly controlled, the quality of anthropometric measurements cannot be guaranteed. However, our checks on data quality for the states in this analysis showed reasonably good data quality. Also, because there is no change in the mean height-for-age $z$ score across the 13-year period for all the states included in this analysis, it is unlikely that a bias in height measurement could affect the observed overweight trend.
Another potential limitation is that changes in program enrollment practice at the state level could have caused changes in the prevalence of overweight. However, our survey among the states showed no systematic changes in the certification criteria or priorities served by states for preschoolers during this period. This supports the conclusion that the overweight trends observed from the study reflects an actual increase in overweight.

The increasing trend in the prevalence of overweight suggests a general shift in behaviors of the population. The genetic component of obesity cannot account for the trends observed. Our analysis cannot delineate fully the reasons for this increase in overweight, because the PedNSS system does not currently collect data on health behavior, dietary intake, physical activity, or other potential contributing factors. Additional research needs to determine the underlying changes in the care of preschool children. For example, could changes in factors affecting birth weight have shifted the birth weight distribution toward higher weights without a proportionate increase in height? Have feeding patterns of young children changed toward fattier, higher calorie foods? Have activity levels of children decreased as TV watching rises?

Overall, this study shows a consistent increase over the past 13 years in the prevalence of overweight among preschool children from low-income families. This finding extends previous analyses to infants and toddlers from the NHANES III for preschoolers of mixed socioeconomic backgrounds. ${ }^{16}$ However, our study differs from the NHANES III study ${ }^{16}$ in that we observed a parallel increase in the prevalence of overweight for preschool girls and boys, whereas Ogden et $\mathrm{al}^{16}$ observed an increase in 
overweight only for preschool girls. Additional research is needed to explore the cause of the trend observed and to find effective strategies for overweight prevention beginning in the preschool years.

\section{ACKNOWLEDGMENTS}

We thank all state nutrition programs participating in the CDC PedNSS, especially the 18 states and the District of Columbia, that provided the data for this study. We also thank Ellen Borland and Jimmy Simmons for providing data management support, and Bettylou Sherry, $\mathrm{PhD}$, for reviewing the document.

\section{REFERENCES}

1. Johnston FE. Health implications of childhood obesity. Ann Intern Med. 1985;103:1068-1072

2. Troiano RP, Flegal KF, Kuczmarski RJ, Campbell SM, Johnson CL. Overweight prevalence and trends for children and adolescents. Arch Pediatr Adolesc Med. 1995;149:1085-1091

3. Gortmaker SL, Dietz WH, Sobol AM, Wehler CA. Increasing pediatric obesity in the United States. Am J Dis Child. 1987;141:535-540

4. Dietz WH. Childhood obesity: susceptibility, cause, and management. J Pediatr. 1983;103:676-686

5. Ross JA, Gilbert G. The National Children and Youth Fitness Study: a summary of findings. J Phys Ed Recreation Dance. 1985;56(suppl 1):45-50

6. Gutin B, Basch C, Shea S, et al. Blood pressure, fitness, and fatness in 5and 6-year-old children. JAMA. 1990;264:1123-1127

7. Shear CL, Freedman DS, Burke GL, Harsha DW, Berenson GS. Body fat patterning and blood pressure in children and young adult-the Bogalusa Heart Study. Hypertension. 1987;9:236-244

8. Rames LK, Clark WR, Connor WE, Reiter MA, Laver RM. Normal blood pressures and the evaluation of sustained blood pressure elevation in childhood: the Muscatine study. Pediatrics. 1978;61:245-251

9. Deschamps I, Desjeuz JF, Machinot S, Rolland F, Lestradet H. Effects of diet and weight loss on plasma glucose, insulin, and free fatty acids in obese children. Pediatr Res. 1978;12:757-760

10. Parra A, Schultz Rb, Graystone JE, Check DB. Correlative studies in obese children and adolescents concerning body composition and plasma insulin and growth hormone levels. Pediatr Res. 1971;5:606-613

11. Tracy VV, De NC, Harper JR. Obesity and respiratory infection in infants and young children. Br Med J. 1971;1:16-18

12. Garn SM. Continuities and changes in fatness from infancy through adulthood. Curr Probl Pediatr. 1985;15:1-47

13. Dietz WJ Jr, Gross WC, Kirkpatrick JA Jr. Blount disease (tibia vara): another skeletal disorder associated with childhood obesity. J Pediatr. 1982;101:735-737

14. Kelsey JL, Acheson RM, Keggi KJ. The body build of patients with slipped capital femoral epiphysis. Am J Dis Child. 1972;124:276-281

15. Dietz WH. Implications and treatment of adolescent obesity. Clin Nutr. 1985;4:103-108

16. Ogden CL, Troiano RP, Briefel RR, Kuczmarski RJ, Flegal KM, Johnson CL. Prevalence of overweight among preschool children in the United States. Pediatrics. 1997;99(4). URL: http://www.pediatrics.org/cgi/ content/full/99/4/e1

17. Centers for Disease Control and Prevention. Nutrition Surveillance Annual Summary 1980. Atlanta, GA: Centers for Disease Control and Prevention; 1983; HHS publication no CDC 83-8295

18. Yip R, Parvanta I, Scanlon K, Borland EW, Russell CM, Trowbridge FL. Pediatric Nutrition Surveillance System-United States, 1980-1991. MMWR. 1992;41:1-24

19. Stefan H, Robert G. WIC Participation in FY 1992. Washington, DC: Center on Budget and Policy Priorities; 1993

20. Burich MC, Murray JR. Study of WIC Participant and Program Characteristics 1990, Final Report. Alexandria, VA: US Department of Agriculture,
Food and Nutrition Service, Office of Analysis and Evaluation; 1992

21. Centers for Disease Control and Prevention. A Guide to Pediatric Weight and Measuring. Atlanta, GA: Centers for Disease Control and Prevention; 1981

22. Centers for Disease Control and Prevention. Enhanced Pediatric Nutrition Surveillance System (PedNSS) Manual. Atlanta, GA: Centers for Disease Control and Prevention; 1994

23. World Health Organization. Physical Status: The Use and Interpretation of Anthropometry. Geneva, Switzerland: World Health Organization; 1995. WHO technical report series

24. Dibley MJ, Staehling NW, Nieburg P, Trowbridge FL. Interpretation of z-score anthropometric indicators derived from the international growth reference. Am J Clin Nutr. 1987;46:749-762

25. Yip R, Trowbridge FL. Pitfalls in the U.S. pediatric growth reference curves. Presented at the 14th Congress of International Nutrition; August 1989; Seoul, Korea

26. Flegal KM. Defining obesity in children and adolescents: epidemiologic approaches. Crit Rev Food Sci Nutr. 1993;33:307-312

27. Obarzanek E. Methodological issues in estimating the prevalence of obesity in childhood. Ann NY Acad Sci. 1993;699:278-279

28. Harlan WR, Landis JR, Flegal KM, Davis CS, Miller ME. Secular trends in body mass in the United States, 1960-1980. Am J Epidemiol. 1988;128: 1065-1074

29. Must A, Dallal GE, Dietz WH. Reference data for obesity: 85th and 95th percentile for body mass index (wt/ht $\left.{ }^{2}\right)$. Am J Clin Nutr. 1991;53: $839-846$

30. Hamill PVV, Drizd TA, Johnson CL, Reed RB, Roche AF, Moore WN. Physical growth: National Center for Health Statistics percentiles. Am J Clin Nutr. 1979;32:607-629

31. Dibley MJ, Goldsby JB, Staehling NW, Trowbridge FL. Development of normalized curves for the international growth reference: historical and technical considerations. Am J Clin Nutr. 1987;46:736-748

32. Centers for Disease Control and Prevention. Update. Prevalence of overweight among children, adolescents, and adults-United States, 1988-1994. MMWR. 1997;46:199-202

33. Centers for Disease Control and Prevention. Prevalence of overweight among adolescents-United States, 1988-1991. MMWR. 1994;43: $818-821$

34. Kuczmarski RJ, Flegal KM, Campbell SM, Johnson CL. Increasing prevalence of overweight among US adults: the National Health and Nutrition Examination Survey, 1960 to 1991. JAMA. 1994;272:205-211

35. Galuska DA, Serdula M, Pamuk E, Siegel PZ, Byers T. Trends in overweight among US adults from 1987 to 1993: a multistate telephone survey. Am J Public Health. 1996;86:1729-1735

36. Malina RM, Little BB, Stern MP, Gaskill SP, Hazuda HP. Ethnic and social class difference in selected anthropometric characteristics of Mexican American and Anglo adults: the San Antonio heart study. Hum Biol. 1983;55:867-883

37. Martorell R, Mendoza FS, Castillo RO, Pawson IG, Budge CC. The short and plump physique of Mexican American children. Am J Phys Anthrop. 1987;73:475-487

38. Graitcer PL, Gentry EM. Measuring children: one reference for all. Lancet. 1981;ii:297-299

39. Habicht JP, Martorell R, Yarbrough C, Malina RM, Klein RE. Height and weight standards for preschool children: how relevant are ethnic differences in growth potential? Lancet. 1974:611-615

40. Martorell R. Child growth retardation: a discussion of its causes and of its relationship to health. In: Blaxter KL, Waterlow JC, eds. Nutritional Adaptation in Man. London, UK: John Libbey; 1985:13-30

41. Trowbridge FL, Marks JS, Lopez de Romana G, Madrid S, Boutton TW, Klein PD. Body composition of Peruvian children with short stature and high weight-for-height. II. Implications for the interpretation for weight-for-height as an indicator of nutritional status. Am J Clin Nutr. 1987;46:411-418 